\title{
Ensino superior nas páginas do Diário dos Campos (1947-1950)
}

\section{Higher Education in the pages of the newspaper Diário dos Campos (1947-1950)}

\author{
Nevio de Campos ${ }^{1}$ \\ Eliezer Felix de Souza ${ }^{1}$
}

\begin{abstract}
RESUMO
Este artigo tem como objeto as discussões sobre ensino superior publicadas no jornal Diário dos Campos, no período entre 1947 e 1950, privilegiando uma análise do texto Precisamos de um ensino superior, escrito por Mario Lima Santos (1947), das matérias que trataram do momento de criação da Comissão Pró-Faculdade de Filosofia de Ponta Grossa, que resultou na autorização de funcionamento da instituição (1948-1949), e das críticas ao grupo político do Partido Social Democrático, que utilizou a fundação da Faculdade de Filosofia como mote eleitoral (1950). Apoia-se no Diário dos Campos e na História Intelectual para reconstituir a atmosfera cultural de Ponta Grossa e a atuação da comunidade intelectual e política no processo que resultou na organização do ensino superior na cidade, sem desconsiderar o movimento intelectual brasileiro que preconizava a expansão do sistema universitário e acreditava na força da formação acadêmica para preparação de profissionais com conhecimento especializado e de elites intelectuais para assumir as funções diretivas nas diferentes esferas do mundo social.
\end{abstract}

Palavras-chave: ensino superior; Diário dos Campos; História Intelectual.

\begin{abstract}
The subject of this article has to do with discussions on higher education which were published in the newspaper Diário dos Campos between 1947 and 1950. Greater emphasis is placed on an analysis of the text We Need Higher Education, written by Mario Lima Santos (1947), on the issues

DOI: $10.1590 / 0104-4060.45080$

1 Universidade Estadual de Ponta Grossa. Ponta Grossa, Paraná, Brasil. Praça Santos Andrade, nº 01.Centro.CEP: 80.060-000.E-mail:ndoutorado@yahoo.com.br e eliezer.felix@hotmail.com
\end{abstract}


about when the Pro-Faculty of Philosophy of Ponta Grossa Commission (1948-1949) was created, that resulted in the operating license for that institution, and on the criticisms to the political group belonging to the Social Democratic Party, which used the foundation of the Faculty of Philosophy as an electoral motto (1950). This article bases itself on Diário dos Campos and on Intellectual History to reconstitute the cultural atmosphere of Ponta Grossa as well as the action taken by the intellectual and political community which resulted in the organization of higher education in the city. Emphasis was also placed on the Brazilian intellectual movement, which professed the expansion of the university system and believed in the power of academic formation to prepare professionals with specialized knowledge and in the intellectual elites to take over directive roles in different spheres of the social world.

Keywords: higher education; Diário dos Campos; Intellectual History.

\section{Introdução}

Este texto tem o objetivo de discutir como o jornal Diário dos Campos $^{2}$ retratou o processo de criação da Faculdade de Filosofia na cidade de Ponta Grossa, Paraná, no período circunscrito entre 1947 e 1950. Existe um conjunto de pesquisas que debate o problema do ensino superior no Brasil, o que torna difícil qualquer tentativa de indicação aqui neste espaço, entretanto, destacamos as pesquisas de Luiz A. Cunha (1980) e Maria de L. Fávero (2000).

No âmbito paranaense há investigadores que se debruçaram a respeito da Universidade Federal do Paraná, como, por exemplo, Rui Wachowicz (1983) e Névio de Campos (2008). Além disso, há vários estudos a respeito de experiências universitárias no interior do Paraná. Em específico da história do ensino superior de Ponta Grossa, há a tese O ensino superior em Ponta Grossa: o tempo das faculdades, escrita por Antonio C. Frasson (2002). Deste mesmo autor, publicado em parceria com Ademir Gebara e Luis Pillati, pode ser acessado o artigo A progênie do ensino superior no interior do Estado do Paraná: a Faculdade de Farmácia e Odontologia de Ponta Grossa (2014). Além disso, existe o texto Da faculdade de filosofia à Universidade Estadual de Ponta Grossa: meio século de ensino superior nos Campos Gerais, escrito por Carmencita de H. M. Ditzel, Niltonci B. Chaves e Rosangela W. Zulian (2004), a dissertação

2 Niltonci Chaves (2001) e Eliezer F. de Souza (2010) ajudam a compreender os discursos do Diário dos Campos. 
Faculdade Estadual de Filosofia, Ciências e Letras de Ponta Grossa/Universidade Estadual de Ponta Grossa: 50 anos do curso de história, produzida por Celia R. de Souza e Silva (2002), a tese A formação do professor de história na Faculdade de Filosofia da Universidade Estadual de Ponta Grossa de 1950 a 1970: propostas curriculares e memórias docentes, de Silvana M. B. Carvalho (2010) e o capítulo de livro Ensino superior no Paraná: avanço da ação estatal (1950-1970), publicado por Névio de Campos (2015).

Este artigo utiliza a imprensa para construir uma interpretação da história da criação de instituições universitárias em Ponta Grossa. Ao cotejar com os arquivos dos números do Diário dos Campos, localizamos um conjunto de publicações que retrata o processo histórico, entre os anos de 1947 e 1950. Privilegiamos três momentos da ação do periódico no processo de criação da Faculdade de Filosofia de Ponta Grossa. O primeiro está demarcado no ano de 1947, cuja expressão fundamental seria a publicação, na edição de 16 de fevereiro de 1947, do texto Precisamos de um ensino superior, escrito por Mario Lima Santos. O segundo, a partir da edição do dia $1^{\circ}$ de outubro de 1948, que tornou pública a existência da Comissão Pró-Escola de Filosofia de Ponta Grossa. Por fim, a posição do Diário dos Campos alterou-se após a criação da referida Faculdade, pois nas edições de 1950 houve uma série de notícias denunciando que a instituição universitária estava associada aos interesses político-partidários dos grupos da cidade de Ponta Grossa que se alinhavam ao governador Moysés Lupion.

\section{Diário dos Campos: algumas observações}

Este jornal, ainda existente, tem sua história centenária. Ele foi criado em 27 de abril de 1907, por Jocob Holzmann, sob a denominação de O Progresso. O jornal começou a ser editado semanalmente. Em 1908, passou a ter três edições por semana. A virada na história jornalística da cidade e do jornal aconteceu com a chegada de Hugo Reis, quando o jornal sofreu significativas mudanças no seu quadro editorial. Desde $1^{\circ}$ de janeiro de 1913 seu nome mudou para Diário dos Campos. Reis permaneceu como proprietário até 1921. Após esse período, o jornal passou por uma sucessão contínua de crises. Foi comprado por Elyseu Campos Mello (advogado e prefeito de Ponta Grossa) e Capitão Vitor Antônio Batista, em 02 de setembro de 1921. Em 1928, José Cadilhe deixou a direção do jornal e a empresa foi assumida por Campos Mello, permanecendo até 1931. 
A partir de então, o jornal passou a vivenciar um período de estabilidade, sob a direção de José Hoffmann ou Juca Hoffmann ${ }^{3}$.

Em geral, a organização do Diário dos Campos tratava de dar visibilidade a uma visão idealizada de Ponta Grossa. Por outro lado, conforme Niltonci Chaves (2015), na coluna Problemas Citadinos, o periódico detalhava as carências existentes, dentre elas a necessidade de consolidação de um projeto educacional de ensino superior. Na avaliação deste historiador, é

[...] possível afirmar que Hoffmann soube utilizar habilmente o jornal como instrumento de ação política. Com um texto bastante característico - recheado por referências a autores, filósofos e escritores do período e pelo ataque direto a adversários e desafetos políticos - Juca tornou-se o principal redator do DC. (CHAVES, 2015, p. 4).

José Hoffmann tecia críticas aos comunistas e aos integralistas, destacando-se em uma posição de caráter liberal. “Ao mesmo tempo, José Hoffmann adotava uma estratégia discursiva clara, baseada na ideia do 'bem comum' e em uma noção de sociedade harmoniosa". (CHAVES, 2015, p. 9). Ainda na esteira de Chaves (2015, p. 6), é fecundo destacar que "José Hoffmann utilizou o jornal como um espaço de ação política. Tanto é assim que, em 1945, foi eleito vereador e seguiu carreira por mais de duas décadas, se valendo, em parte desse tempo, do DC para divulgar e defender suas ideias". Em termos precisos, Chaves (2015) ainda sustenta que:

A produção discursiva do Diário dos Campos influenciou a opinião pública ponta-grossense e projetou José Hoffmann como um intelectual preocupado com a vida local, fato que ele soube capitalizar na medida em que se tornou um dos políticos mais influentes do interior do Paraná até meados da década de 1960. (CHAVES, 2015, p. 10).

3 “José Hoffmann, ou Juca, como era mais conhecido, nasceu em Ponta Grossa em 21 de julho de 1904. Faleceu em 18 de março de 1969. Proveniente de família católica, José Hoffmann estudou nos Colégios Sant'Ana, dirigido pelas Irmãs Missionárias Servas do Espírito Santo, no Instituto João Cândido e também no Colégio Diocesano São Luiz, todos em Ponta Grossa. Completou seus estudos na Escola Coração de Jesus em São Paulo. Não freqüentou curso superior, mas foi um autodidata, reunindo conhecimento nas mais variadas áreas como a filosofia, a política, a economia. José Hoffmann começou a projetar-se na vida social, cultural e política de Ponta Grossa a partir do início da década de 1930. Em 1931, adquiriu o principal jornal de Ponta Grossa, o já tradicional Diário dos Campos, instalando-o na casa onde anteriormente funcionara o empório atacadista de seu pai”. (CHAVES, 2001, p. 47). 
Carlos Eduardo Vieira (2007) analisa a imprensa no âmbito nacional e paranaense. Com relação ao Paraná, o autor referencia a atuação dos jornais Diário da Tarde e Gazeta do Povo, os quais tiveram papel de destaque na esfera política e social, aderindo, também, à causa educacional. Já em nível nacional, Vieira destaca que o jornal $O$ Estado de São Paulo teve ação relevante na causa educacional, sobretudo na década de 1920. Naquele período, Fernando Azevedo lançou os famosos inquéritos sobre educação e, a partir deles, resultaria, em 1932, a publicação do Manifesto dos Pioneiros da Educação Nova. Compartilhamos da afirmação de que "[...] o jornal impresso diário é parte de uma estrutura midiática de enorme impacto e, cada vez mais, diversificada ação política e cultural". (VIEIRA, 2007, p. 15). Ele pode ser “[...] entendido como lugar de produção, veiculação e circulação dos discursos - assume uma função importante no processo de formação das representações sobre o mundo". (VIEIRA, 2007, p. 16).

A opinião pública é uma faceta importante que está associada ao jornalismo. Em relação a esse aspecto, o grupo ligado à direção do Diário dos Campos dizia que "[...] só a ela nos inclinaremos reverente porque na soberania coletiva está inclusa a nossa própria soberania. Somos um órgão soberano. De um povo soberano". (O PROGRESSO, 16 jun. 1910). No entendimento de Hugo Reis, opinião seria a oportunidade de manifestação pública no espaço do jornal. Contudo, o entendimento desse conceito vai mais além. Marco Morel (2008, p. 33) faz algumas interrogações a respeito disso: "o que significa esta expressão [opinião pública]?”. Ele sustenta que “[...] há quem a tome de forma literal como personagem ou agente histórico dotado de vontade, tendência e iniciativa próprias". (MOREL, 2008, p. 33). Mas no geral, "a expressão opinião pública é polissêmica - também polêmica”. (MOREL, 2008, p. 33).

Formação da opinião das pessoas. Fazer com que elas criem polêmicas em determinadas questões, seria essa uma das principais imposições dos meios de comunicação impressos. A chamada opinião pública não é recente no jornalismo e suas principais características datam das duas primeiras décadas do século XVIII, na Europa. Carlos Eduardo Vieira (2007) argumenta que o conceito de opinião pública está associado à questão da modernidade. Partindo desse pressuposto, conforme Vieira (2007, p. 19), "[...] a modernidade foi concebida pelos seus principais arautos como a ação edificante da razão que - por meio da ciência, da tecnologia, da instrução e das políticas sociais - universalizaria um novo modo de pensar e agir". Nesse aspecto, os jornais representariam um importante aliado, não só no papel de incentivador de manifestações pedagógicas, como ainda exerceriam a importante função de polemização. Por isso, a imagem da imprensa estaria "[...] associada ao seu poder de influenciar a sociedade, de formar a chamada opinião pública". (VIEIRA, 2007, p. 19). Segundo Peter 
Burke e Asa Brigs (2006, p. 78), “[...] genericamente, o jornais contribuíram para aparecimento da opinião pública, termo que tem primeiro registro em francês por volta de 1750, em inglês em 1781; em alemão, em 1793".

Os impressos da cidade de Ponta Grossa nasceram naquele movimento dos primeiros anos da República, quando na imprensa:

[...] Estamparam-se à exaustão as idéias e imagens do progresso pretendidas pela nova ordem. Ao lado da política, a urbanização foi um de seus grandes temas, veiculada pela festejada modernização do aparelhamento jornalístico, com novas oportunidades tecnológicas para a produção e reprodução do texto e da imagem, em que desdobrou a estética literária parnasiana emoldurada por guirlandas art-nouveaux. Conglomerados jornalísticos consolidaram-se naqueles anos eufóricos, introduzindo novas relações no mercado do impresso. O debate político, a veiculação do quadro econômico e a exaltação das transformações urbanas foram conduzidas pela propaganda e pela publicidade, que se profissionalizavam, a serviço de grupos estrangeiros e dos primeiros governos republicanos... frase de ordem: o Brasil civiliza-se. (MARTINS, 2008, p. 79-80).

Os discursos da imprensa se centraram numa sociedade que buscava incisivamente o progresso. A imprensa tornou-se grande imprensa, otimizada por uma conjuntura favorável. Essa transformação apoiou-se no tão propagado incentivo à alfabetização, à insurgente indústria do papel e ao aparecimento do telefone e telégrafo, que se configuraram como agilizadores do processo de transmissão dos dados que eram elaborados pela redação. À alfabetização, aliás, pedra de toque para os republicanos, acrescente a formação do leitor, que encontrou naquele periodismo o suporte preferencial para o exercício da leitura e das letras.

As transformações, no campo da comunicação impressa, seguiram as mudanças no contexto social, político e econômico da sociedade brasileira. Essas alterações aconteceram em maior proporção nos grandes centros urbanos brasileiros. Ponta Grossa, na passagem do século XIX para o século XX, ainda apresentava-se como uma cidade em processo de formação. Os primeiros periódicos surgiram na cidade no final do século XIX. Porém, todos foram efêmeros. O jornal O Progresso/Diário dos Campos despontou nesse processo. Sua história está associada a inúmeros proprietários e editores, contudo, sem deixar de manter a representação de que caberia à imprensa o papel de projetar entre a opinião pública uma ideia de cidade, de cultura, de civilização, assim como de indicar as mazelas existentes na Ponta Grossa da primeira metade 
do século XX. Ao mesmo tempo, a ação social deste periódico materializou a atuação pública de personagens que assumiram as funções de intérpretes do que seria e do que poderia ser Ponta Grossa, enfim, de mediadores culturais e de representantes políticos.

\section{Ensino superior nas páginas do Diário dos Campos}

No item anterior, expusemos alguns aspectos do Diário dos Campos. A educação foi um tema recorrente nas páginas do periódico, desde o momento de sua criação, em 1907, como atesta a dissertação de Eliezer F. de Souza (2010). Na década de 1930, o processo de criação da Faculdade de Farmácia e Odontologia ganhou destaque em suas páginas, conforme evidencia Antonio C. Frasson (2002). Além disso, as análises de Niltonci Chaves (2001, p. 33) indicam que na "[...] década de 1930, em Ponta Grossa, coube importante papel à imprensa escrita em relação à fixação de representações aceitas pela sociedade em geral".

Na segunda metade de década de 1940, o ensino superior retornou ao debate do Diário dos Campos, cujo redator-chefe continuava a ser José Hoffmann. Precisamos de um ensino superior foi o título dado por Mario Lima Santos $^{4}$ ao seu texto publicado em 16 de fevereiro de 1947. O artigo inaugurou a discussão pública a respeito do ensino superior. Não é possível datar os primeiros encontros dos grupos envolvidos com essa discussão, pois é comum essas ideias serem ventiladas em diversos momentos e de modo descentralizado. Entretanto, o Diário dos Campos constituiu-se em um espaço privilegiado de divulgação e conformação das ideias e ações que resultaram na criação de faculdades na cidade.

O professor Mario Lima Santos, estrategicamente, associou ensino superior ao progresso material da cidade de Ponta Grossa. Ele iniciou seu texto com esse argumento: "Alguém deixará de concordar na afirmativa generalizada, de que Ponta Grossa como principal centro demográfico do interior do Estado, pela sua importância comercial, industrial e agrícola, faz jus de há muito a um estabelecimento de ensino superior". (DIÁRIO DOS CAMPOS, 16 abr. 1947). Essa imagem construída pode ser encontrada na obra de Carmencita Ditzel (2007, p. 68): “[...] entre 1920-1945 a cidade se firmou como polo regional no Paraná, exercendo grande influência na sua área geo-econômica. Ocupou a posição de

4 Mario Lima Santos foi professor e advogado. Nos textos do Diário dos Campos assinava como professor de Lógica e Psicologia. 
segunda cidade do Estado, contando com 38.417 habitantes (censo de 1940), dos quais $74,5 \%$ fixados no meio urbano".

A preocupação de Mario Lima é demarcar uma função social do ensino superior entre a opinião pública de Ponta Grossa. Em um contexto em que os ares do progresso e da modernização ainda conformavam as representações, associar o ensino superior ao avanço material ressoava, de modo muito mais forte, entre os que poderiam mobilizar diferentes forças políticas e intelectuais para encampar esse tipo de projeto.

A imagem de que instituições de ensino superior desempenham um papel importante no mundo social ganhou dimensão internacional com as políticas expansionistas da França de Napoleão, quando no início do século XIX foi estabelecida a Universidade do Estado como modelo, assim como com os investimentos da Prússia, com a criação da Universidade de Berlim. (CHARLE; VERGER, 1996). Essa tendência ganhou notoriedade nos debates e nas próprias políticas públicas para o ensino superior no Brasil, já com a vinda da Família Real. (CUNHA, 1980; FÁVERO, 2000). Porém, ganhou materialidade, logo após, a criação do Império brasileiro, quando foram fundadas as escolas de medicina, engenharia e direito. A produção e/ou reprodução de saberes nos espaços universitários e a própria formação de profissionais com competência técnica para operacionalizarem as demandas sociais do mundo moderno justificava a criação e expansão de instituições de ensino superior.

Esse argumento, já secular, fez-se presente no primeiro parágrafo do texto de Mario Lima, quando inaugurou o debate sobre a necessidade da existência de instituições de ensino superior em Ponta Grossa. Essa reinvenção argumentativa correspondia, de forma concreta, às representações da modernidade e do progresso que se faziam presentes, desde o final do século XIX, na cidade de Ponta Grossa. (CHAVES, 2001; 2015; DITZEL, 2007; SOUZA, 2010). Conforme Niltonci Chaves (2001, p. 16), “[...] a década de 1930 pode ser caracterizada como um momento de grandes transformações para Ponta Grossa. Além do crescimento de seu contingente populacional, a cidade também registrou um acentuado desenvolvimento de seu quadro urbano".

Mario Lima recuperou, em sua primeira exposição, o argumento que povoou os debates dos intelectuais brasileiros dos oitocentos e novecentos de que o ensino superior deveria estar condicionado à existência de fatores materiais e demográficos que o justificassem. Neste aspecto, ele reatualizou esse argumento ao postular que Ponta Grossa possuía todas as condições que historicamente foram defendidas pelas lideranças políticas e intelectuais do Brasil. O professor Lima, nos dois parágrafos seguintes de seu texto, detalhou os dados demográficos e econômicos da cidade a fim de demonstrar ao leitor que, a exemplo de Curitiba, Ponta Grossa poderia comportar instituições de ensino superior. 
Ao lado desse argumento que continha forte repercussão social, Mario Lima tratou de discutir os elementos específicos de uma instituição de ensino superior. Tão logo acalentou as mentes e os corações daqueles que esperavam do ensino superior respostas às demandas de ordem puramente material, o autor do texto destacou em um novo parágrafo a seguinte assertiva: "mas, nem só de pão vive o homem". (DIÁRIO DOS CAMPOS, 16 fev. 1947). No quarto parágrafo do texto, ele fez alusão aos elementos internos do campo intelectual que justificavam a criação de instituições universitárias. De forma contundente, ele se dirigiu aos grupos intermediários da cidade, aqueles que estavam entre os potenciais herdeiros dos espaços universitários, quando asseverou que: “[...] não é bastante que plantemos os nossos produtos agrícolas, nem que criemos a nossa pecuária; não é bastante que importemos o que aqui não é fabricado para a satisfação de nosso comércio; nem tão pouco que manufaturemos os produtos de nossa indústria". (DIÁRIO DOS CAMPOS, 16 fev. 1947).

Mario Lima traduzia em sua escrita a condição agrícola e comercial da cidade. Além disso, tocava em um elemento bastante sensível para aquele contexto, pois, conforme dados presentes em seu texto, Ponta Grossa totalizava sessenta mil habitantes, sendo que cinquenta mil pertenciam à população urbana. Mostrava-se uma cidade com população que residia no espaço urbano, porém, transparecia na narrativa do autor que a urbe de meados do século XX respirava as representações e as práticas típicas de cidades de tradição rural. (SCHIMANSKI, 2007). Ao lado desse diagnóstico pouco animador, Mario Lima partilhava de uma visão bastante idealizada da cidade: "Ponta Grossa, é no concerto dos demais municípios do Estado, o que São Paulo é na Federação: o mais importante de seus centros demográficos. Justamente, por isso, a nossa cidade precisa de impor-se e valer-se à sua altura". (DIÁRIO DOS CAMPOS, 16 fev. 1947).

Esse diagnóstico de Mario Lima, corroborado na pesquisa de Elizabete Shimanski (2007), seguiu acompanhado de um prognóstico bastante convincente, pois na sequência ele defendeu que: “[...] tudo isso, representa o nosso progresso material, mas o homem, não é só matéria, não é apenas o ser físico, há qualquer coisa de imponderável, que representa o espírito". (DIÁRIO DOS CAMPOS, 16 fev. 1947). Aqui reside a transição discursiva de Mario Lima. Reconhece a importância do capital material na sociedade do século XX. Neste aspecto, aproxima o projeto universitário de Ponta Grossa das representações dos grupos que controlavam os meios e as forças produtivas. Ele sintetiza sua compreensão disso ao afirmar que "toda essa parte material, revela, não resta dúvida, a nossa pujança física”. (DIÁRIO DOS CAMPOS, 16 fev. 1947). Em seguida, assevera: "[...] mas, falta-nos o outro lado, o outro termo do binômio que realiza o homem na sua integralidade: matéria e espírito". (DIÁRIO DOS 
CAMPOS, 16 fev. 1947). Aqui transparece o elemento central que justificaria a criação do ensino superior em Ponta Grossa, pois indica que o progresso material se fazia presente, mas estava ausente um projeto de formação cultural do paranaense da região de Ponta Grossa. A proposta do grupo, liderado por esse intelectual ponta-grossense, resultou na criação da Faculdade de Filosofia, Ciências e Letras.

Na sequência da argumentação de Mario Lima é possível observar sua compreensão do que seria a natureza humana: "[...] o homem, é diferente dos animais irracionais: ele não tem somente necessidade, tem, também, aspirações, as quais se satisfazem pelo coração e pelo cérebro, em última análise pelo espírito". (DIÁRIO DOS CAMPOS, 16 fev. 1947). Além do mais, é perceptível nas manifestações desse professor a tentativa de indicar os caminhos promissores à própria cidade: “[...] é por isso, que nós - ponta-grossenses de nascimento e ponta-grossenses de coração - sentimos que algo nos falta para completar a nossa situação de centro civilizado". (DIÁRIO DOS CAMPOS, 16 fev. 1947).

A participação do Diário dos Campos no movimento de construção de uma opinião pública favorável à criação do ensino superior teve continuidade. $\mathrm{Na}$ edição de $1^{\circ}$ de outubro de 1948, publicou uma nota que detalhava o processo de criação da Comissão Pró-Escola de Filosofia de Ponta Grossa. A nota trazia como subtítulo: Constituída uma comissão de ilustres professores para coordenar esse movimento. Já, no início, destacava: “[...] de algum tempo a esta parte vem sendo cogitado, em nossos círculos intelectuais, a criação, em Ponta Grossa, de uma Escola de Filosofia, Ciências e Letras". (DIÁRIO DOS CAMPOS, $1^{\circ}$ out. 1948). Mais adiante, foram mencionados os integrantes dessa comissão:

Para coordenar esse movimento já esboçado em nossa cidade, e que foi debatido pela imprensa ainda há pouco, foi constituída uma comissão de ilustres nomes do nosso magistério e assim composta: Dr. Mario Lima Santos, presidente, Dr. José Pinto Rosa, vice-presidente, Dr. Lourival Santos Lima [advogado], secretário, Prof. Valdemiro Lopes [?], tesoureiro. (DIÁRIO DOS CAMPOS, $1^{\circ}$ out. 1948).

Em seguida, a nota do referido periódico mencionou que "[...] vai ser dirigido, em breve um memorial às autoridades competentes, expondo essa justa reivindicação da mocidade ponta-grossense, a qual, sem dúvida, será satisfeita pelos nossos poderes estaduais, após as demarches que as fazem mister para tão notável obra cultural". (DIÁRIO DOS CAMPOS, $1^{\circ}$ out. 1948). Por fim, em tom ufanista declarou: "[...] cumpre-nos louvar a oportuna iniciativa dos cultos 
intelectuais conterrâneos, visando a criação de tão importante educandário superior, a que Ponta Grossa faz jus pelos seus foros de progresso e adiantamento social". (DIÁRIO DOS CAMPOS, $1^{\circ}$ out. 1948).

As observações de Eno Wanke (1999, p. 213-214) nos ajudam a ampliar a lista de integrantes do grupo que liderou o processo de criação de instituições de ensino superior em Ponta Grossa, pois atentam que "[...] na fase final, destacaram-se, além de Mario Lima Santos que foi o primeiro Secretário da Faculdade, os euclidianos Dr. Joaquim de Paula Xavier, que acabou sendo seu primeiro Diretor, o Dr. Raul Pinheiro Machado, o Dr. José Pinto Rosas e outros". O Diário dos Campos publicou matéria sobre o grupo da comissão, na qual ressaltava:

Prosseguindo as manifestações de apoio e aplausos ao movimento pró-Faculdade de Filosofia de Ponta Grossa, acabam de enviar ofícios à mencionada comissão os srs. Dr. Faris Antonio Michaele e estudante João Amaral de Almeida, respectivamente presidentes das entidades culturais "Centro Cultural Inter-americano" e "Centro Cívico Regente Feijó, dessa cidade". (DIÁRIO DOS CAMPOS, 21 out. 1948).

Os fragmentos destacados evidenciam que o projeto de ensino superior contou com a organização de um grupo de intelectuais que residia em Ponta Grossa e que ocupava as funções no magistério do ensino secundário e/ou exercia as profissões de médicos e advogados. Essa iniciativa indica uma posição de organização e mobilização de um grupo de bacharéis que enxergava no ensino superior um espaço de ação e de distinção social. Esse grupo que estava envolvido com inúmeros projetos culturais na cidade, dentre eles o Centro Cultural Euclides da Cunha (CCEC), tinha reconhecimento no principal órgão de debate público de Ponta Grossa, o jornal Diário dos Campos.

A ação dos intelectuais de Ponta Grossa ganhou reconhecimento entre os grupos políticos do Estado do Paraná. No Diário dos Campos se destacou que:

Esse movimento sadio de alevantamento do nosso nível cultural, através da fundação dos primeiros cursos superiores do interior do Estado, em Ponta Grossa, já encontrou eco nos círculos estaduais e, em breve será apresentado, na Assembleia Legislativa do Estado, um projeto de lei visando a concretização do nobre objetivo. (DIÁRIO DOS CAMPOS, 21 out. 1948). 
Além disso, o referido jornal ressaltou que os intelectuais iriam a Curitiba para tratar, com representantes da política estadual, da viabilização e do encaminhamento do processo de criação dos primeiros cursos de ensino superior em Ponta Grossa:

A Comissão que se vem batendo pela concretização de tão valioso escopo e que tem à frente os professores Drs. Mario Lima Santos, José Pinto Rosas, Lourival Santos Lima e Valdemiro Lopes, logo irá a capital do Estado, a fim de entender-se com os poderes competentes, com respeito ao magno assunto. (DIÁRIO DOS CAMPOS, 21 out. 1948).

Em 08 de novembro de 1949, com o Decreto ${ }^{0} 8.837$, o governador do Paraná (Moysés Lupion) criou a Faculdade de Filosofia, Ciências e Letras de Ponta Grossa. Tão logo criada, o grupo mentor dessa instituição, na companhia do conjunto de docentes, reuniu-se no dia 12 de novembro de 1949 para o ato de instalação da referida Faculdade. Consta na Ata de instalação que:

Aos doze dias do mês de novembro do ano de mil novecentos e quarenta e nove, nesta cidade de Ponta Grossa, Estado do Paraná, no Salão Nobre do Colégio Estadual "Regente Feijó", às vinte horas, reunidos os professores abaixo assinados, comigo secretário e com o Dr. Joaquim de Paula Xavier, diretor, por este considerada instalada a Faculdade de Filosofia, Ciências e Letras de Ponta Grossa, nos termos do Decreto Estadual N. 8837, de 8 de novembro de 1949, publicado no Diário Oficial N. 214, de 9 de novembro. (FACULDADE DE FILOSOFIA..., 12 nov. 1949, p. 1).

O jornal Diário dos Campos deu visibilidade ao debate que defendia a criação de cursos de ensino superior em Ponta Grossa, o que culminou com a criação da Faculdade de Filosofia. Entretanto, no momento das eleições para governador do Estado do Paraná, esse periódico criticou os integrantes do Partido Social Democrático (PSD), agremiação pertencente ao então governador Moysés Lupion 5 . Na edição de 02 de junho de 1950, com o título "Escola de filosofia e propaganda eleitoral", o Diário dos Campos condenou os usos partidários

5 José Hoffmann “[...] elegeu-se vereador em 1947, deputado em 1950 e prefeito de Ponta Grossa entre 1955 e 1958 e 1962 e 1966 . Durante quase toda sua carreira política foi filiado e militante do PTB, criado em 1945 por Getúlio Vargas, de quem se dizia profundo admirador. Anteriormente, Hoffmann fora um dos membros mais ativos do PSD em Ponta Grossa”. (CHAVES, 2001, p. 48). 
do projeto da Faculdade de Filosofia, sem sequer terem iniciadas as atividades acadêmicas. O jornal descreveu que a pirotecnia devia-se à comemoração pelo reconhecimento da instituição junto ao governo federal. Na noite do mesmo dia da assinatura presidencial de reconhecimento "[...] os rojões cortaram os céus e não faltou mesmo os acordes de uma banda de música, ouvidos em disco". (DIÁRIO DOS CAMPOS, 02 jun. 1950). Além disso, "discursos e manifestações partidárias. O PSD e a 'Sociedade dos Amigos' exultaram e ostentaram o fato celebrado como resplendente troféu de vitória”. (DIÁRIO DOS CAMPOS, 02 jun. 1950). O jornal denunciou que se tratava da terceira comemoração, na tentativa de convencer a opinião pública de que a referida Faculdade já estava transformada em reduto eleitoral. O periódico especulou que essa crítica seria interpretada como posição "[...] facciosa acerca de um empreendimento que, não há negar, deve ser acolhido com aplausos por todos os ponta-grossenses". (DIÁRIO DOS CAMPOS, 02 jun. 1950). No entanto, emendou sua resposta a essa possível interpretação:

Não estamos combatendo e nunca combateremos a Escola de Filosofia ou outra qualquer medida que objetive conceder ao nosso município um pouco daquilo a que ele faz jus. O que criticamos é esse alarido com o único objetivo de fazer-se propaganda partidária, propaganda do PSD. Que venha, pois, a Escola de Filosofia, não como o preço de nossa consciência cívica, não como o preço pelo qual pretende o PSD, comprar os votos de nosso eleitorado consciente, mas como uma parte das vindicações devidas a Ponta Grossa. Que venha, pois, a Escola de Filosofia, se é que, apesar de tudo, ainda virá, ainda que tenhamos de assistir mais meia dúzia de comemorações para fins eleitorais do PSD... (DIÁRIO DOS CAMPOS, 02 jun. 1950).

O ambiente eleitoral continuou a ditar o ritmo dos debates no Diário dos Campos. Em 06 de junho de 1950, o referido periódico estampou na primeira página o título "A Escola de Filosofia e o preço de nossa consciência cívica". O jornal reiterou sua condenação ao afirmar que "[...] o PSD está procurando explorar eleitoralmente, de maneira que não pode deixar de suscitar a nossa desaprovação, o projeto pertinente à Faculdade de Filosofia de Ponta Grossa". (DIÁRIO DOS CAMPOS, 06 jun. 1950). Mais adiante o periódico denunciou que:

O PSD, que dispõe da diretoria do Colégio Regente Feijó, deliberou, por intermédio desta, conclamar os estudantes para uma manifestação, no dia de ontem. É sabido que, levados por natural e louvável espírito de disciplina, 
os alunos desse e de outros educandários estão sempre prontos a atender a esses chamamentos dos professores. E a manifestação transformou-se, não no enaltecimento de um ato governamental, mas em verdadeiro comício político-eleitoral. (DIÁRIO DOS CAMPOS, 06 jun. 1950).

Na mesma matéria, o texto se expressou na direção de que ao jornalismo caberia a tarefa de erguer-se contra o atentado à consciência. Assim, “[...] entendemos que não cabe ao PSD fixar o preço da consciência cívica do altivo povo ponta-grossense. É ingenuidade julgarem os pessedistas que o preço da nossa consciência cívica pode ser fixado pela Faculdade de Filosofia”. (DIÁRIO DOS CAMPOS, 06 jun. 1950). A redação ganhou adjetivações contundentes, pois se reiterou que a crítica ao uso eleitoral da Faculdade de Filosofia não representava uma posição contrária àquela instituição. Mas, "anelamos que ela se torne realidade". Seguia, ao dizer que "[...] condenamos os métodos postos em prática pelos 'mestres' e maiorais pessedistas. O povo, certamente, pensa como nós. As urnas, em 3 de outubro, dirão quem está com a razão". (DIÁRIO DOS CAMPOS, 06 jun. 1950).

A julgar pela edição de 29 de julho de 1950, o ambiente entre os grupos ligados a Moysés Lupion e a Bento Munhoz da Rocha Neto ficou muito mais beligerante, pois naquele momento o Diário dos Campos acusou a direção da Faculdade de Filosofia de cercear a liberdade política de estudantes que decidiram criar uma comissão pró-candidatura de Bento Munhoz. Dizia a nota: “[...] ameaçados os alunos da Escola de Filosofia por haverem organizados um comitê pró candidatura de Bento Munhoz". (DIÁRIO DOS CAMPOS, 29 jul. 1950). No corpo do texto, o jornal usou palavras com tom impositivo, ao registrar que iria telegrafar ao Presidente da República, ao Ministro da Educação, ao Senado e à Câmara dos Deputados. Além disso, asseverou que "[...] iremos nós também ocupar a tribuna, em praça pública, para causticar esse desmando, se ele se consumar ou se a compressão seguir". (DIÁRIO DOS CAMPOS, 29 jul. 1950).

De acordo com Aída Manzani Lavalle, citada por Niltonci Chaves (2001, p. 45), mesmo o Diário dos Campos sofrendo confrontação da elite política local, ainda era "[...] o mais respeitado pela população de Ponta Grossa. Era nos segmentos mais populares da sociedade ponta-grossense que José Hoffmann e o Diário dos Campos tinham maior aceitação". Este periódico estabelecia a temperatura do debate político, dizia Aída Lavalle. (CHAVES, 2001, p. 45). Nas edições de meados do ano de 1950, já não se observa menção às ações do grupo responsável pela criação da Faculdade de Filosofia, mas sim críticas às tentativas de associação direta, entre o estabelecimento do ensino superior em Ponta Grossa e o governo de Moysés Lupion. O discurso recorrente do periódico 
é de que os cursos de ensino superior chegaram a Ponta Grossa por mérito do povo ponta-grosssense. Estava em plena disputa o controle da opinião pública, pois se, um dos lados, procurava vincular a criação da Faculdade ao governo do PSD, o outro grupo buscava desqualificar essa associação, pois naquele momento, o então redator-chefe do Diário dos Campos, José Hoffmann, era candidato a deputado pelo PTB, cuja agremiação apoiava a candidatura de Bento Munhoz da Rocha nas eleições para governador que aconteceriam no dia 03 de outubro de 1950.

\section{Considerações finais}

O debate a respeito da criação do ensino superior não pode ser compreendido apenas como um ato de grupos de ponta-grossenses, nem como uma ação benevolente do governo de Moysés Lupion. Ao contrário, o movimento de criação da Faculdade de Filosofia deve ser interpretado no contexto brasileiro que, desde a década de 1930, estimulava a criação desse tipo de instituição de ensino superior, particularmente a partir da Reforma Francisco Campos, em 1931, assim como no contexto favorável ao ensino superior no Estado do Paraná, pois desde 1912, uma parcela de políticos e intelectuais lutou pela consolidação da Universidade do Paraná, cujo processo se materializou em 1946. (CAMPOS, 2008; WACHOWICZ, 1983). Além do mais, a partir das reformas de Gustavo Capanema, na década de 1940, passou a ser exigido o diploma de ensino superior para o exercício do magistério no ensino secundário. Ademais, a passagem pelo ensino superior passou a ser requisito fundamental para sacralizar as trajetórias dos principais agentes responsáveis pela modernização do Brasil e do próprio Paraná. (MICELI, 2001).

Nos anos de 1940 ocorreu o processo de consolidação da universidade no Estado do Paraná. Essa nova situação resultou da ação dos grupos envolvidos com o ensino superior e das políticas públicas federais que estabeleceram a possibilidade de transformar as faculdades privadas e confessionais em universidades públicas federais. Em 1946, a Universidade do Paraná foi oficializada com a aglutinação das Faculdades de Medicina, de Engenharia, de Direito e Filosofia, Ciências e Letras. Em 1950, a instituição foi transformada em Universidade Federal do Paraná.

Esse conjunto de fatores constituiu as condições para o estabelecimento do

ensino superior em Ponta Grossa. É relevante ressaltar que o ambiente cultural e social de Ponta Grossa estava condicionado por um processo de organização de 
inúmeros espaços culturais e sociais, como, por exemplo, a Escola Normal (1924) ${ }^{6}$, o Ginásio Regente Feijó (1927) ${ }^{7}$, o CCEC $(1947)^{8}$ e a Faculdade de Filosofia, Ciências e Letras de Ponta Grossa (FFCL-PG) (1949). Além disso, merece destaque a organização de inúmeras escolas religiosas na cidade, entre as quais destacamos o Colégio Santana ${ }^{9}$ e o Colégio Sagrada Família ${ }^{10}$. Entretanto, a criação das primeiras instituições de ensino superior, em Ponta Grossa, não pode ser compreendida sem a atuação das lideranças culturais e de políticos de âmbito local e regional que defenderam o processo de interiorização de instituições universitárias.

Nesse ambiente, o Diário dos Campos assumiu a posição de defesa dos mais variados projetos sociais e culturais. Esse periódico atuou não apenas como agente de divulgação de notícias, mas como conformador de um ideário societário para Ponta Grossa, pois ao posicionar-se, defendeu a necessidade de criação de instituições de ensino superior. Nesse sentido, participou do movimento que culminou na efêmera Faculdade de Farmácia e Odontologia, na segunda metade da década de 1930, assim como do processo de discussão e criação da Faculdade de Filosofia, no final dos anos de 1940. A participação do periódico consistiu em dar visibilidade ao grupo responsável pela criação da Faculdade de Filosofia e a conformar uma opinião pública favorável à criação de instituições de ensino superior em Ponta Grossa.

\section{REFERENCIAS}

BURKE, P.; BRIGGS, A. Uma história social da mídia: de Gutemberg à internet. Rio de Janeiro: Zahar, 2006.

CAMPOS, N. de. Intelectuais paranaenses e as concepções de universidade (1892-1950). Curitiba: Editora UFPR, 2008.

CAMPOS, N. de. Ensino superior no Paraná: avanço da ação estatal (1950-1970). In: ROIZ, D. da S. (Org.). A história intelectual: entre instituições e letrados na historiografia brasileira. Jundiaí: Paco Editorial, 2015. p. 287-316.

CARVALHO, S. M. B. A formação do professor de história na Faculdade de Filosofia da Universidade Estadual de Ponta Grossa de 1950 a 1970: propostas curriculares e memórias docentes. Tese (Doutorado em Educação) - Universidade Federal do Paraná, Curitiba, 2010.

6 Maria Isabel Nascimento (2008).

7 Maísa Remer (2013).

8 Carmencita Ditzel (2007)

9 Gisele Chornobai (2002).

10 Elizabeth Johansen (2003). 
CHARLE, C.; VERGER, J. História das universidades. São Paulo: UNESP, 1996.

CHAVES, N. B. A cidade civilizada: discursos e representações sociais no jornal Diário dos Campos na década de 1930. Curitiba: Aos Quatro Ventos, 2001.

CHAVES, N. B. Os “problemas citadinos” em uma "cidade civilizada": estratégias discursivas de um intelectual polivalente no jornal Diário dos Campos - Ponta Grossa (década de 1930). In: CONGRESSO INTERNACIONAL DE HISTÓRIA UEPG-UNICENTRO, 2., 2015, Ponta Grossa. Anais... Ponta Grossa: UEPG, 2015. p. 1-12.

CHORNOBAI, G. Q. L. Igreja Católica, Educação Feminina e Cultura Escolar em Ponta Grossa (Paraná): a Escola Normal de Sant'Ana (1947-1960). Dissertação (Mestrado em Educação) - Programa de Pós-Graduação em Educação, Universidade Federal do Paraná, Curitiba, 2002.

CUNHA, L. A. A universidade temporã: da Colônia à Era de Vargas. Rio de Janeiro: Francisco Alves, 1980.

CUNHA, L. A. A universidade reformada: o golpe de 1964 e a modernização do ensino superior. Rio de Janeiro: Francisco Alves, 1988.

CUNHA, L. A. A universidade crítica: ensino superior na República populista. Rio de Janeiro: Francisco Alves, 1989.

DIÁRIO DOS CAMPOS. Ponta Grossa, 1947-1950.

DITZEL, C. de H. M. Imaginário e representações: o integralismo dos Campos Gerais (1932-1955). Ponta Grossa: UEPG, 2007.

DITZEL, C. de H. M.; CHAVES, N. B.; ZULIAN, R. W. Da faculdade de filosofia à Universidade Estadual de Ponta Grossa: meio século de ensino superior nos Campos Gerais. In: DITZEL, C. de H. M. et al. Visões de Ponta Grossa: cidade e instituições. Ponta Grossa: UEPG, 2004. p. 182-193.

FACULDADE DE FILOSOFIA, CIÊNCIAS E LETRAS DE PONTA GROSSA. Ata da instalação da Faculdade de Filosofia, Ciências e Letras de Ponta Grossa realizada no dia 12 de novembro de 1949. Livro 1, p. 1.

FÁVERO, M. de L. de A. Universidade do Brasil: das origens à construção. Rio de Janeiro: UFRJ/INEP, 2000.

FRASSON, A. C. O ensino superior em Ponta Grossa: o tempo das faculdades. Tese (Doutorado em Educação) - Programa de Pós-Graduação em Educação, Universidade Metodista de Piracicaba, Piracicaba, 2002.

FRASSON, A. C.; GEBARA, A.; PILLATI, L. A progênie do ensino superior no interior do Estado do Paraná: a Faculdade de Farmácia e Odontologia de Ponta Grossa (2014). Revista Histedbr, Campinas, n. 58, p. 33-43, set. 2014.

HOLZMANN, E. Cinco histórias convergentes. Curitiba: Requião, 1966. 
JOHANSEN, E. De católicos poloneses a ponta-grossenses católicos: a Escola Sagrada Família - 1933-1945. Dissertação (Mestrado em História) - Programa de Pós-Graduação em História, Universidade Federal do Paraná, Curitiba, 2003.

MARTINS, A. L. Imprensa em tempos de Império. In: MARTINS, A. L.; LUCA, T. R. de (Org.). História da imprensa no Brasil. São Paulo: Contexto 2008. p. 45-81.

MICELI, S. Intelectuais à brasileira. São Paulo: Companhia das Letras, 2001.

MOREL, M. Os primeiros passos da palavra impressa. In: MARTINS, A. L.; LUCA, T. R. de (Org.). História da imprensa no Brasil. São Paulo: Contexto 2008. p. 23-43.

NASCIMENTO, M. I. M. A Primeira Escola de Professores dos Campos Gerais-PR. Ponta Grossa: UEPG, 2008.

PARANÁ. Decreto n ${ }^{\circ} 8.837$, de 08 de novembro de 1949. Cria, na cidade de Ponta Grossa, uma Faculdade de Filosofia, Ciências e Letras. Diário Oficial do Estado do Paraná. Curitiba, 08 dez. 1949.

O PROGRESSO. Ponta Grossa, 1910.

REMER, M. M. Z. O ensino secundário público paranaense: o Ginásio Regente Feijó, Ponta Grossa (1927-1961). Tese (Doutorado em Educação) - Programa de Pós-Graduação em Educação, Pontifícia Universidade Católica do Paraná, Curitiba, 2013.

SCHIMANSKI, E. Conservadorismo e tradição em Ponta Grossa: representação social, mito ou realidade local? Dissertação (Mestrado em Ciências Sociais Aplicadas) - Universidade Estadual de Ponta Grossa, Ponta Grossa, 2007.

SILVA, C. R. de S. e. Faculdade Estadual de Filosofia, Ciências e Letras de Ponta Grossa/Universidade Estadual de Ponta Grossa: 50 anos do curso de história. Dissertação (Mestrado em Educação) - Programa de Pós-Graduação em Educação, Universidade Estadual de Ponta Grossa, Ponta Grossa, 2002.

SOUZA, E. F. Intelectuais, modernidade e discurso educativo no jornal Diário dos Campos (1907-1928). Dissertação (Mestrado em Educação) - Programa de Pós-Graduação em Educação, Universidade Estadual de Ponta Grossa, Ponta Grossa, 2010.

VIEIRA, C. E. Jornal diário como fonte e como tema para a pesquisa em história da Educação: um estudo da relação entre imprensa, intelectuais e modernidade nos anos de 1920. In: OLIVEIRA, M. T. de (Org.). Cinco estudos em história e historiografia da Educação. Belo Horizonte: Autêntica, 2007. p. 11-40.

WACHOWICZ, R. C. Universidade do mate: história da UFPR. Curitiba: APUFPR, 1983. WANKE, E. T. Faris Michaele: cronologia da vida e da obra. Rio de Janeiro: Edições Plaquette, 1999. 